\title{
Crystallization of Syndiotactic Polypropylene
}

\author{
Tadashi Asanuma*I, Shosuke Nakanishi*', Tetsunosuke Shiomura*', and Toshiji Kanaya*2 \\ -1 Osaka Research Laboratory, Mitsui Toatsu Chemicals Inc., Takasago, Takaishi, Osaka, 592 Japan \\ ${ }^{\circ}$ Institute for Chemical Research, Kyoto University, Uji, Kyoto, 611 Japan
}

\begin{abstract}
The crystallization behavior of syndiotactic polypropylene with high stereoregularity was evaluated by density measurement, wide angle X-ray scattering (WAXS) and small angle X-ray scattering (SAXS). The peaks of scattering patterns could be observed by WAXS immediately after the crystallization started, but not by SAXS. The peaks of scattering patterns could be only observed by SAXS when the crystallinity calculated from the density was above $25 \%$.
\end{abstract}

\section{Introduction}

Syndiotactic polypropylene ( $s P$ ) has been previously produced by Natta [1]. Since then improvements in catalyst and polymerization methods have been made to produce a highly syndiotactic polymer [2]. However, the stereoregularity of $s P P$ did not exceed about 0.6 for the syndiotactic pentad fraction. This value is very small comparing with 0.9 for the isotactic pentad fraction of commercial isotactic polypropylene (i PP). Recently, many kinds of metallocene catalysts were produced for the polymerization of propylene [3]. Ewen and coworkers prepared a highly syndiotactic polypropylene using iso. propylidene (cyclopentadienyl-1.fluorenyl) zirconium di. chloride and aluminoxane [4]. The crystalline structures of this $s P P$ have been already reported [5]. It showed a good transparency as well as a good balance of stiffness and impact strength (6).

The crystallization behavior of $s \mathrm{PP}$ of low stereoregularity was observed by Boor [7] and Lotz [8] using differential scanning calorimetry (DSC). However, the crys. tallization behavior of $s \mathrm{PP}$ with high stereoregularity, particularly its initial crystallization behavior, is almost unknown. This is the topic of this report.

\section{Experimental}

$s P P$ was prepared by the same procedure described in a previous paper [5] (syndiotactic pentad fraction, limit. ing viscosity of tetrahydronaphthalene solution at $412 \mathrm{~K}$, melting point by DSC and glass transition temperature by DMA were $0.915,1.40 \mathrm{dL} / \mathrm{g}, 425 \mathrm{~K}$ and $277 \mathrm{~K}$, re- spectively). After melting at $513 \mathrm{~K}, s \mathrm{PP}$ was beld be tween two stainless steel boards, and transferred to the bath controlled at a required temperature. The sample was kept at the constant temperature for a predetermined period and quenched to $203 \mathrm{~K}$ to stop crystalliza. tion. A sample prepared by quenching from $513 \mathrm{~K}$ to $203 \mathrm{~K}$ was used as a reference.

The densities were measured at $243 \mathrm{~K}$ using a pycnometer. The melting temperature was measured by a differential scanning calorimeter (Perkin Elmer model 4) at a heating rate of $10 \mathrm{~K} / \mathrm{min}$ under nitrogen atmosphere. Wide angle X-ray scattering (WAXS) measurements were performed using $\mathrm{Ni}$-filtered $\mathrm{Cu} \mathrm{K} \boldsymbol{\alpha}$ radiation generated from a RAD.2C (Rigaku Denki Co. Ltd.. Japan) and dif. fractometer having a pinhole collimation system equipped with a scintillation counter. The scattering intensity was measured in the scattering angle $2 \theta$ range from 5 to $55^{\circ}$. Small angle $X$-ray scattering (SAXS) measurements were perforormed with $6 \mathrm{~m}$ point focusing SAXS camera at the High-Intensity X-ray Laboratory of Kyoto University. Ni-filtered $\mathrm{Cu} K \alpha$ radiation from a $3.5 \mathrm{~kW}$ rotating-anode X-ray generator (RU-1000C3, Rigaku Denki Co. Ltd., Japan), a Franks-type double-focusing point collimator, and two-dimensional position sensitive pro. portional counter were used for SAXS measurement. The scattering intensity after subtracting the background was circularly averaged since the scattering patters were azimuthally isotropic. The measurements were carried out in the scattering vector $Q(4 \pi \theta / \lambda)$ range of 0.01 to $0.2 \mathrm{~A}^{-1}$. The samples were kept at about $243 \mathrm{~K}$ for measurement. 


\section{Results and Discussion}

The crystallinities at various crystallizing times were calculated from densities using $0.930 \mathrm{~g} / \mathrm{cm}^{3}$ for $100 \%$ crystalline and $0.851 \mathrm{~g} / \mathrm{cm}^{3}$ for $0 \%$ crystalline $s P P$. The results are shown in Fig.1. The initial crystallization rate, as given by the initial slope of the curves in Fig. 1 , was small at $303 \mathrm{~K}$ and at $373 \mathrm{~K}$. and showed a miximum at $323 \mathrm{~K}$. The crystallization rate decreased when the crystallization temperature exceeded $323 \mathrm{~K}$. The crystallinity of $s \mathrm{PP}$ increased with time, and levelled off

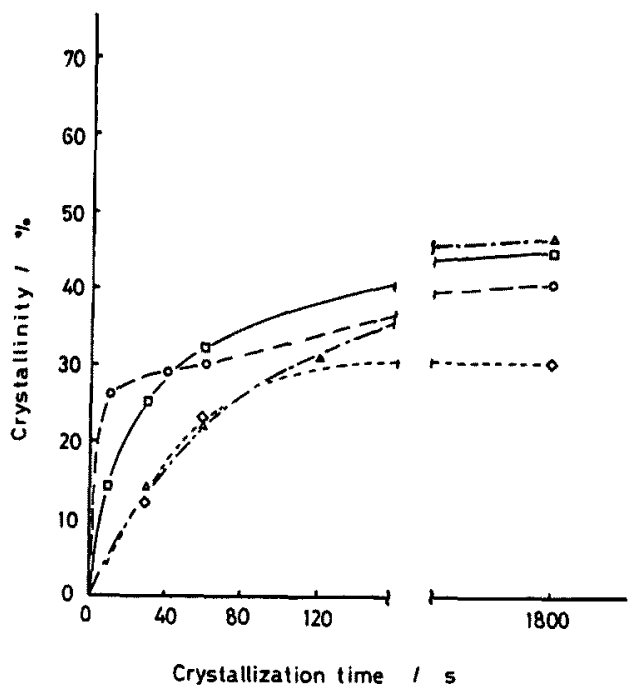

Fig. 1 Crystallinity as a function of crystallization time. Crystallization temperatures are: $\diamond, 303 \mathrm{~K} ; 0$, $323 \mathrm{~K}, \square, 353 \mathrm{~K}$; and $\triangle .373 \mathrm{~K}$.

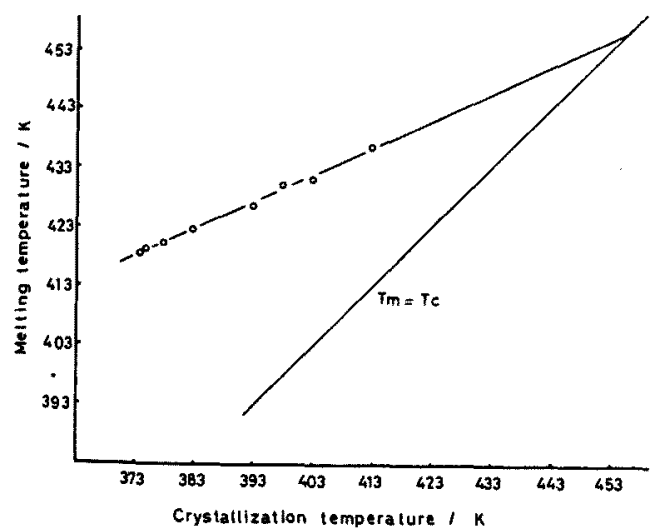

Fig. 2 Relation between crystallization temperature and melting temperature. after $1800 \mathrm{~s}$. This maximum crystallinity increased with crystallization temperature, but was found to saturate above $353 \mathrm{~K}$.

These results suggested that the crystallization rate

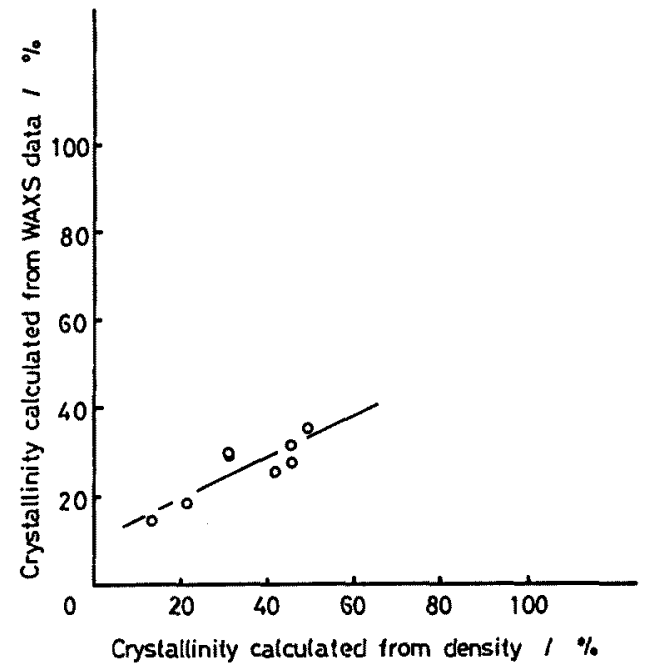

Fig. 3 Relation between the crystallinities estimated from the WAXS patterns and from the densities.

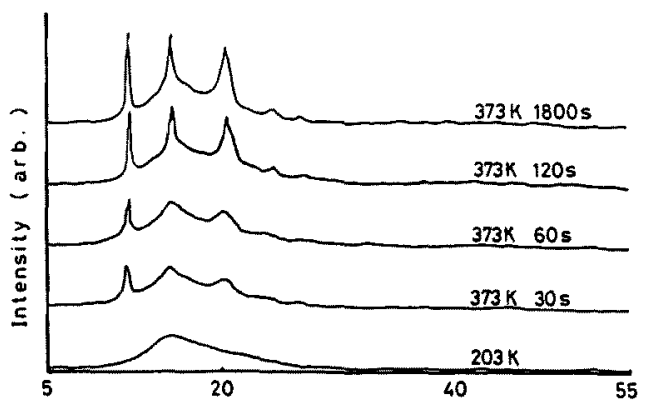

$2 \theta /$ deg

Fig. 4 Effect of crystallization time on WAXS patterns of sPP's crystallized at $373 \mathrm{~K}$.

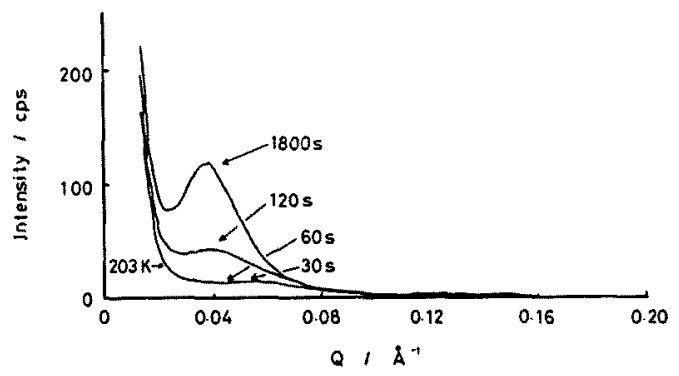

Fig. 5 Effect of crystallization time on SAXS patterns of $s$ PP's crystallized at $373 \mathrm{~K}$. 
and maximum crystallinity of $s P P$ were very small comparing with those of $i \mathrm{PP}$, whose maximum crystallinity reached $58 \%$ at $323 \mathrm{~K}$ and $69 \%$ at $373 \mathrm{~K}$ after $1800 \mathrm{~s}$. Fig. 2 shows the relationship between crystallization temperature $(\mathrm{Tc})$ and melting temperature $(\mathrm{Tm})$ for $s P P$. By extrapolating the lineare relationship to $\mathrm{Tm}=\mathrm{Tc}$, the equililrium melting temperature is estimated (9). The thermodynamic melting temperature of $s P P$ is $456 \mathrm{~K}$ and that of $i$ PP is $483 \mathrm{~K}(10)$ as shown in Fig. 2. So the differences between the melting temperature and the crys. tallization temperature are almost the same when the samples are crystallized at $303 \mathrm{~K}$ and $353 \mathrm{~K}$ for $s \mathrm{PP}$. and $323 \mathrm{~K}$ and $373 \mathrm{~K}$ for $i \mathrm{PP}_{2}$, respectively.

In Fig. 3 , the crystallinities calculated from the WAXS patterns according to the literature (11) using the pattern at $203 \mathrm{~K}$ as an amorphous sample are compared with the crystallinities calculated from densities. The values of crystallinities obtained by the two methods were very different. The reason was not clear. In this study the crystallinities calculated from densities were used.

The WAXS patterns for different time periods at 373 $\mathrm{K}$ are shown in Fig. 4. Peaks are observed after only 30 $s$, and the peaks become more prominent with time, i. e., 60,120 , and $1800 \mathrm{~s}$. This phenomenon means a growth of the crystal.

The SAXS patterns of the same samples shown in Fig. 4 are given in $F$ ig. 5 . In this figure, the scattering patterns of the sample held for $30 \mathrm{~s}$ and $60 \mathrm{~s}$ at $373 \mathrm{~K}$ were the same as that of the sample directly quenched to $203 \mathrm{~K}$ after molding. Therefore, the long-period ordering perhaps was not promoted after 30 and $60 \mathrm{~s}$, at $373 \mathrm{~K}$.

The SAXS patterns from the samples prepared by holding for $1800 \mathrm{~s}$ at several temperatures are shown in Fig. 6. The peak intensities increased and the Q-values of the peaks became smaller with the increase of annealing

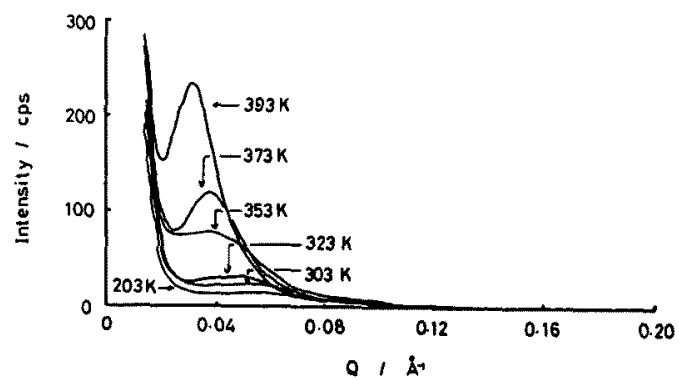

Fig. 6 Effect of temperature on SAXS patterns of $s$ PP's crystallized for $30 \mathrm{~min}$.

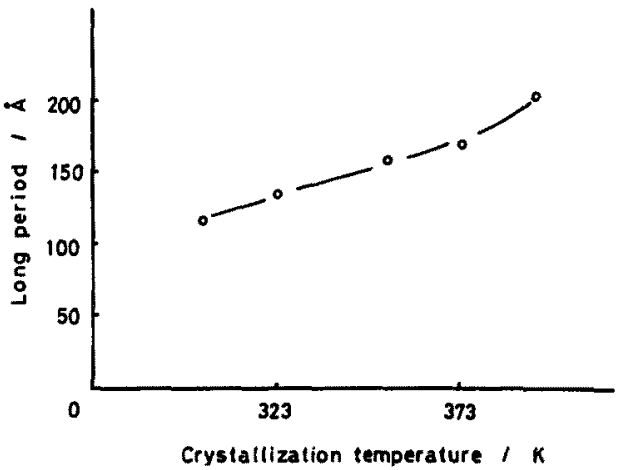

Fig. 7 Relation between the long period and crystalliza. tion temperature.

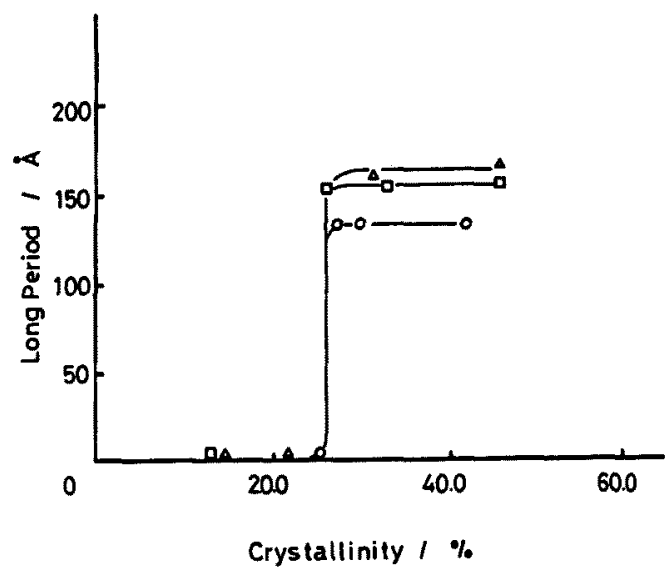

Fig. 8 Relation between the long period and crystallin. ity calculated from densities: $O, 323 \mathrm{~K} ; \square, 353 \mathrm{~K} ; \Delta$. $373 \mathrm{~K}$.

temperature. Fig. 7 shows the long period, estimated from the peak positions of the scattering patterns in Fig. 6 , as a functional crystallization temperature. The long period became larger as the crystallization temperature increases.

The relation between the long period and the crystallinity is shown in Fig. 8. The long period appeared only after the crystallinity reached $25 \%$. Although the long period was independent of crystallinity, the intensities of the peaks in the SAXS patterns increased whth increasing crystallinity.

The initial crystallization rates calculated from the sample densities showed a maximum at $323 \mathrm{~K}$. This result may be reasonable because the crystallization is nucleation controlled at high temperatures and is 
diffusion-controlled at low temperatures. These two processes have an opppsite temperature dependence to each other, and hence a maximum in rate is observed.

More detailed studies concerning the mechanism of generation of the long period are needed. But these results confirmed that the long period increased whih the crystallization temperature. The crystallinity should exceed about $25 \%$ in order for the long period of $s \mathrm{PP}$ to be observed by SAXS.

\section{References}

1. G. Natta, I. Pasquon, P. Corradini, M.Perald, M. Pegoraro, and A. Zambelli, Rend. Acc. Naz. Lincel, 28, 539 (1960).

2. G. Natta, I. Pasquon, and A. Zambelli, J. Am. Chem. Soc., 84, 1488 (1962).

3. H. Sinn, W. Kaminsky, H. J. Vollmer, and R. Woldt, Angew. Chem, 92, 396 (1980), W. Kaminsky, K. Kulper, H. H. Brintzinger, and F. R. W. P. Wild, Angew.
Chem., 97, 507 (1985), T. Mise, S. Miya, and H. Yamazaki, Chem. Lett., 1989, 1853.

4. J. A. Ewen, R. L. Jones, A. Razavi, and J. D. Ferrara, J. Am. Chem. Soc., 110. 6255 (1988).

5. Y. Chatani, H. Maruyama, K. Noguchi, T. Asanuma, and T. Shiomura, J. Polym. Sci., Part C. 28. 393 (1990).

6. T. Asanuma and T. Shiomura, Kobunshi Kako, 41, 28 (1992).

7. J. Boor Jr and A. Youngman, J. Polym. Sci., Part A-1, 4. 1861 (1966).

8. A. Lovinger, B. Lotz, and D. D. Davis, Polymer, 31. $2253(1990)$.

9. J. D. Hoffman and J. J. Weeks, J. Res. Natl. Bur. Stand., A66, 13 (1962).

10. Y. S. Yadav and P. C. Jain, Polymer, 27, 721 (1986).

11. A. Weidinger and P. H. Hermance, Makromol. Chem., 50, 98 (1961). 